\title{
Alkylphenol ethoxylates and their degradation products in abiotic and biological samples from the environment ${ }^{1}$
}

\author{
P. de Voogt*, O. Kwast, R. Hendriks and N. Jonkers
}

Institute for Biodiversity and Ecosystem Dynamics IBED, Department of Environmental and Toxicological Chemistry, University of Amsterdam, Nieuwe Achtergracht 166, 1018 WV Amsterdam, The Netherlands.

\begin{abstract}
Analytical procedures were optimized for the analysis of surfactants and their degradation products in abiotic and biological samples. The procedures include filtration of water samples and Soxhlet extraction of sediment or sludge samples, followed by automated SPE (C-18 cartridge) and cleanup $\left(\mathrm{Al}_{2} \mathrm{O}_{3}\right)$. For biological materials a matrix dispersed solid phase extraction method was used.

Using these methods, information was obtained about the efficiency of the sewage treatment plants, the changes in oligomer ratios of APEO between influent and effluent, the formation and occurrence of metabolites, and the internal concentrations that may occur when mussels are exposed to APEO in the field.
\end{abstract}

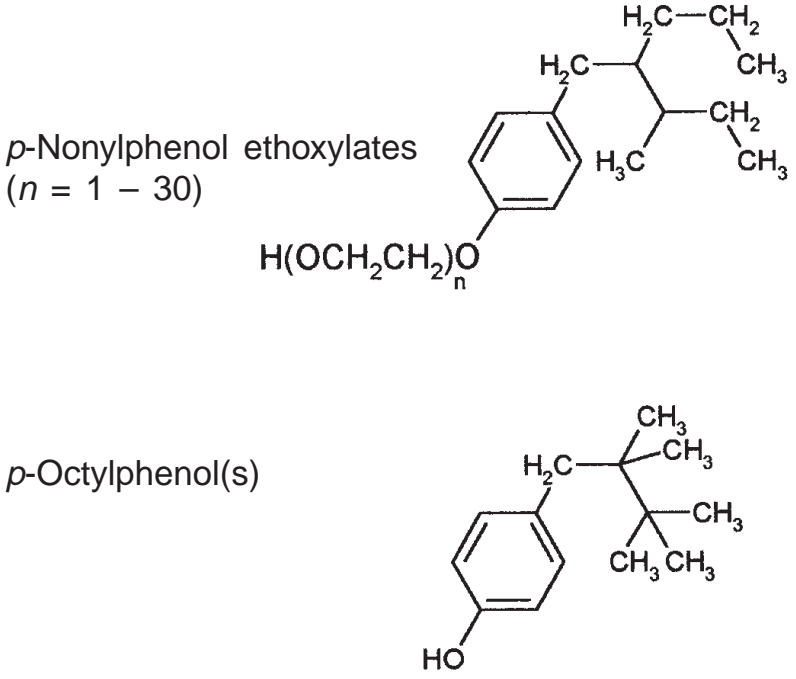

Figure 1. Structure of nonylphenol ethoxylates and octylphenols.

sewage treatment plants (STP), in aquatic ecosystems, and in organisms exposed to STP discharges. In order to assess the environmental risk of $\mathrm{A}_{9} \mathrm{PE}$, it is necessary to study their biodegradation in detail. Therefore, the microbial degradation routes of APEO by naturally occurring bacterial consortia were studied by identifying metabolites in an experimental laboratory set up.

\section{Materials and methods}

\section{Sample preparation}

Abiotic samples were taken by third parties, preserved with formaldehyde to prevent biodegradation, and stored at $4{ }^{\circ} \mathrm{C}$. ment. Optimization of already existing analytical procedures for APEO was done in order to study their fate in and around

\footnotetext{
${ }^{1}$ This paper was presented at the Meeting "Les Pertubateurs Endocriniens: aspects analytiques, toxicologiques et réglementaires", Cercle des Sciences Analytiques, Paris, January 21, 2000.
} 


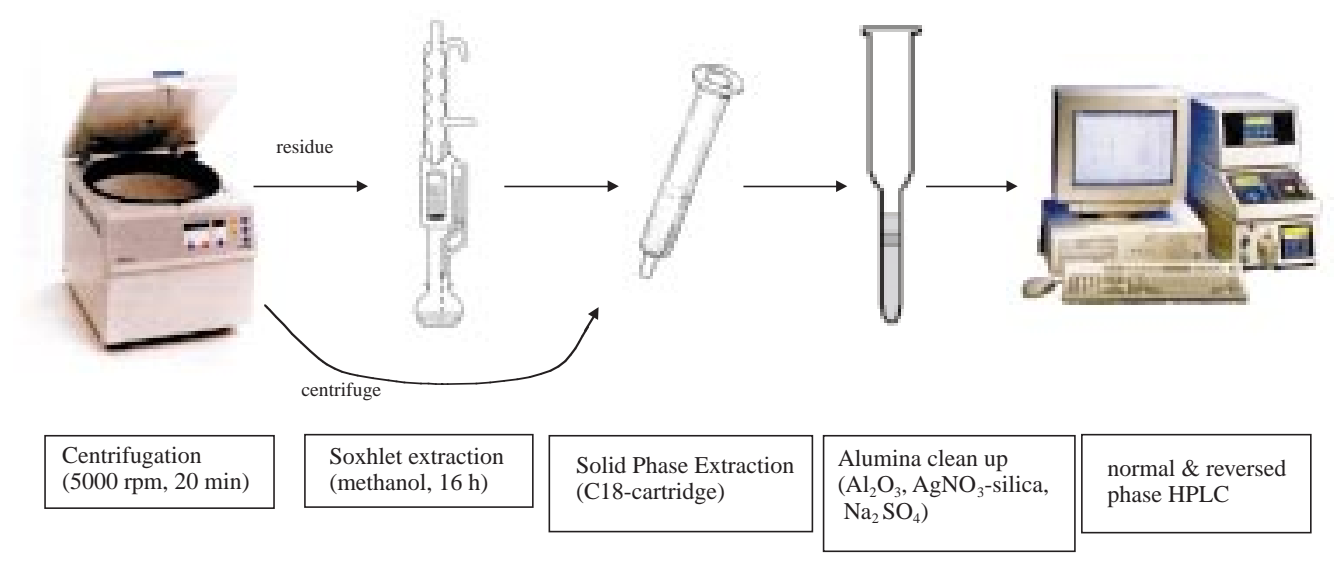

Figure 2. General procedure used for the determination of APEO in abiotic samples.

The analytical procedure used for abiotic samples is a slight modification of an earlier published method [2] (see also Fig. 2). Phase separation was achieved by filtration (waste water samples) or centrifugation (sewage sludge), after which the residue was Soxhlet extracted. The water phase and the Soxhlet extract were extracted and concentrated by Solid Phase Extraction (C-18 cartridge), followed by an Alumina clean up.

Biological samples (trout and mussel) were treated with another method, called Matrix Solid Phase Dispersion (MSPD) extraction (Fig. 3). In this method, the extraction, concentration and clean up are combined in one step [3]. The biological tissue is mixed with the C-18 SPE material and ground until a powder is obtained. In this way, an optimal contact between the sample and extraction material is achieved. The solid mixture is loaded into a glass column on top of a layer of alumina. APEO analytes are eluted from the column with methanol.

\section{HPLC analysis}

To obtain the maximum amount of information, the samples were analyzed on both normal and reversed phase HPLC, using fluorescence detection, as described earlier [2]. With normal phase HPLC, APEO are separated by their ethoxylate chain length (see Fig. 4a), whereas with reversed phase HPLC, the APEO are separated by alkyl chain length (see Fig. 4b).

To gain insight in the ethoxylate chain distribution of the APEO in the samples, normal phase HPLC analysis was performed. This pattern was compared to several APEO standards, and the most similar standard was used for quantitation. In most cases, this was a standard mixture containing an average of four ethoxylate units.

The quantification was performed by reversed phase HPLC, which integrates oligomers and isomers with a certain alkyl chain length into one relatively broad peak ( $c f$. Fig. 4b). Separate peaks are thus observed for octylphenol

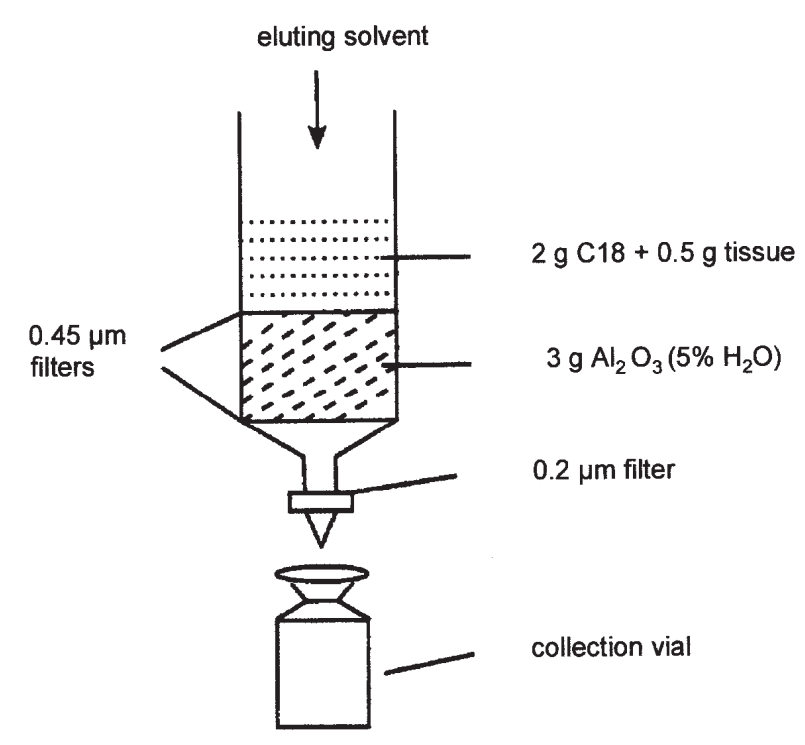

Figure 3. Schematic representation of the matrix solid phase dispersion method employed for biological samples.

isomers, nonylphenol isomers, the sum of the octylphenol ethoxylate oligomers, and the sum of the nonylphenol ethoxylate oligomers ( $c f$. Fig. 5).

\section{LC/MS analysis}

LC/MS was used for metabolite identification. To that end an electrospray interface was employed. Details of this method will be published elsewhere [4]. Alkylphenol ethoxylates were detected in positive mode, and all metabolites in the negative mode. Without the use of eluent additives, APEO tend to form both sodium and ammonium adducts, in a ratio of $2: 1$. To simplify these spectra, the 
a)

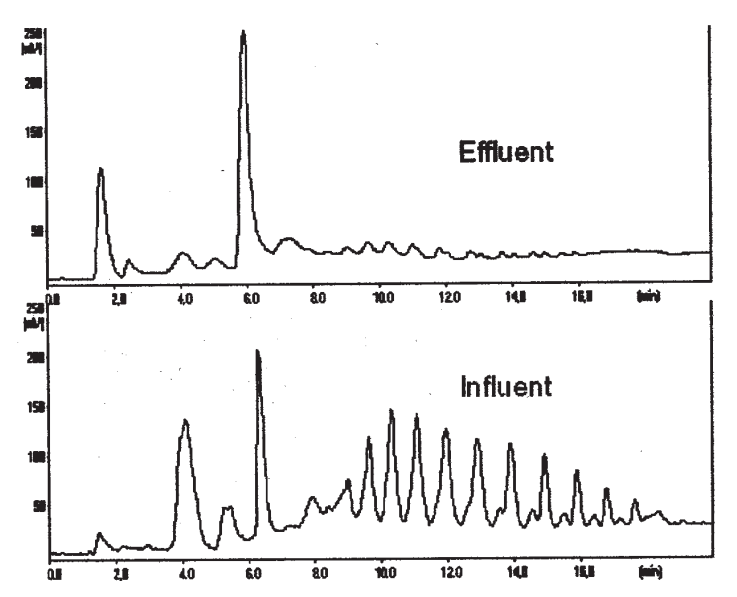

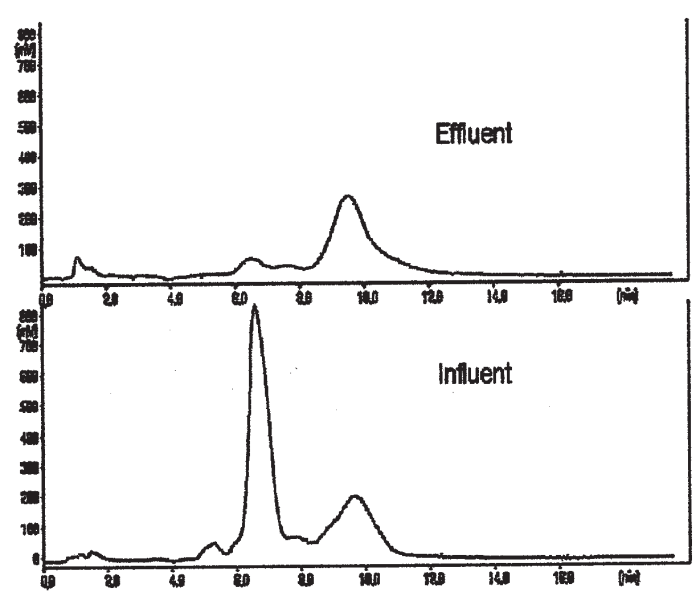

Figure 4. a, NP-HPLC-FLU chromatograms of aqueous samples from an industrial STP, showing the typical EO oligomer distribution; b, RP(C18)-HPLC-FLU chromatograms of same STP samples as in figure 4a

formation of ammonium adducts was enforced by adding ammonium acetate to the methanol/water mobile phase.

\section{Biodegradation}

A laboratory scale set up [4] was used to study the biodegradation of APEO, in which aerated river Rhine water (spiked with a technical mixture of $10 \mathrm{mg} / 1 \mathrm{~A}_{9} \mathrm{PEO}$ containing oligomers with 2 to 16 ethoxylate groups) is pumped continuously over a glass column filled with glass beads, on which a biofilm is present.

Samples were taken daily and enriched using C18-SPE. Analyses were performed using reversed phase LC/MS in positive and negative ionization mode, as indicated above.

\section{Results and discussion}

\section{Optimization studies}

\section{Contamination}

A difficulty in the analysis of APEO is that because of their many applications, traces of APEO are present in a lot of materials. All plastics or rubbers in the laboratory (package material, tubes, gloves) have to be checked for contamination or replaced by glass or teflon to reduce blank levels. Figure 5 shows an example of the coelution of extracted materials from different brands of laboratory rubber gloves with $\mathrm{AP}(\mathrm{EO})$ standards in reversed phase LC with fluorescence detection. Extracts were obtained by immersing the glove during $10 \mathrm{~min}$ in methanol in an ultrasonic bath. Only one brand out of seven tested did not show interfering coextracted materials. Though the latter were not further identified, they are likely to be alkylphenol ethoxylates, as comparison with APEO standards (see bottom Fig. 5) reveals.

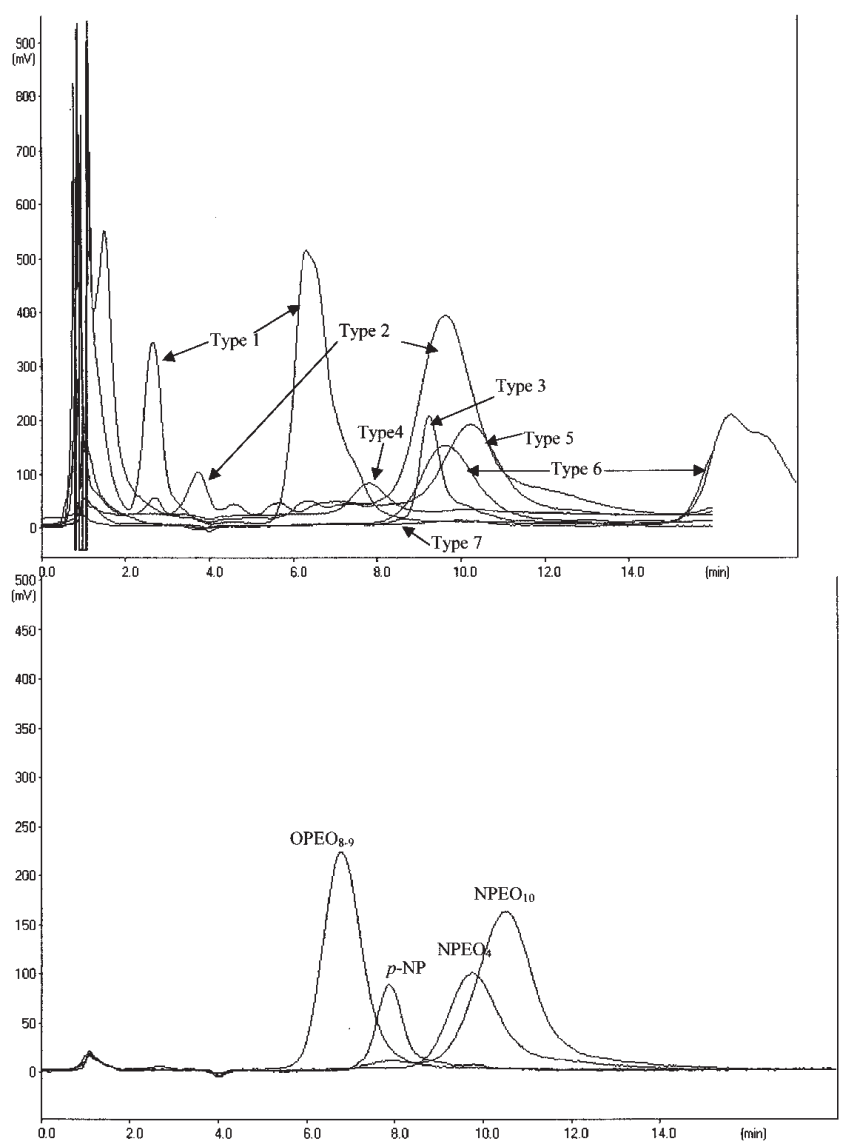

Figure 5. Reversed-phase LC chromatograms recorded with fluorescence detection of $\mathrm{AP}(\mathrm{EO})$ calibration standard mixtures (bottom) and ethanol extracts of various brands of commercial laboratory gloves (top). Note, in top chromatogram, the occurrence of major peaks in the standard elution area, probably due to presence of $\mathrm{AP}(\mathrm{EO})$ in glove rubbers. Fluorescence conditions: $\operatorname{Ex} \lambda=225 \mathrm{~nm}, \operatorname{Em} \lambda=301 \mathrm{~nm}$. 


\section{Dissolved and particle-adsorbed fractions}

Another difficulty lies in the interpretation of aqueous sample results. For water samples, often the reported concentration is the total concentration of both the water and solid fraction of the sample (as in the present study), whereas others report the aqueous concentration after filtration of the sample. For sediment samples in this study, the centrifuge residue was processed, and the measured concentration is based on this fraction (which still contains some water). Such differences in sampling make a comparison between different studies awkward. For a better interpretation of results, it is important to know if the APEO are mainly present in the water or solid fraction, or if both fractions are important. To investigate which fraction of the STP sample matrices is the most relevant, influents and effluents from one STP were filtered and sludges were centrifuged. Both the water and the solid fraction were processed. Also, unfiltered samples were directly extracted by SPE, to obtain a total concentration. Table I shows the contribution of solidsassociated and dissolved fractions to total concentrations in samples from a domestic STP. It is clear from this table that the contribution from solids-associated and dissolved fractions may vary substantially, and depend on the actual contents of solids in water samples or water in sludge samples. Total concentrations are in reasonable agreement with summation of separate fractions.

\section{Recoveries}

Good recoveries were obtained for both the abiotic and MSPD procedures: recoveries varied from $98 \%$ for nonyland octylphenol to $>80 \%$ for the APEO with long ethoxylate chains (average: 10 units).

\section{Matrix dispersed solid phase extraction}

For the analysis of biological samples a modified Matrix Solid-Phase Dispersion method with sequential cleanup has been developed to isolate and purify APEOs and alkylphenols in biological tissues. Elution profile, sequential cleanup adsorbent and experimental set up were optimized. Octadecylsilica was used as the solid phase for matrix dispersion.
Methanol was found to be the optimal eluting solvent for APEOs. Aluminum oxide turned out to be much more efficient for removing the interferences coeluting from the dispersed C-18/matrix mixture than e.g., silica (see Fig. 6).

Quantitative analysis was done by reversed-phase HPLC with fluorescence detection. The optimized procedure was applied to analyze both fish and mussel samples (see Fig. 7).

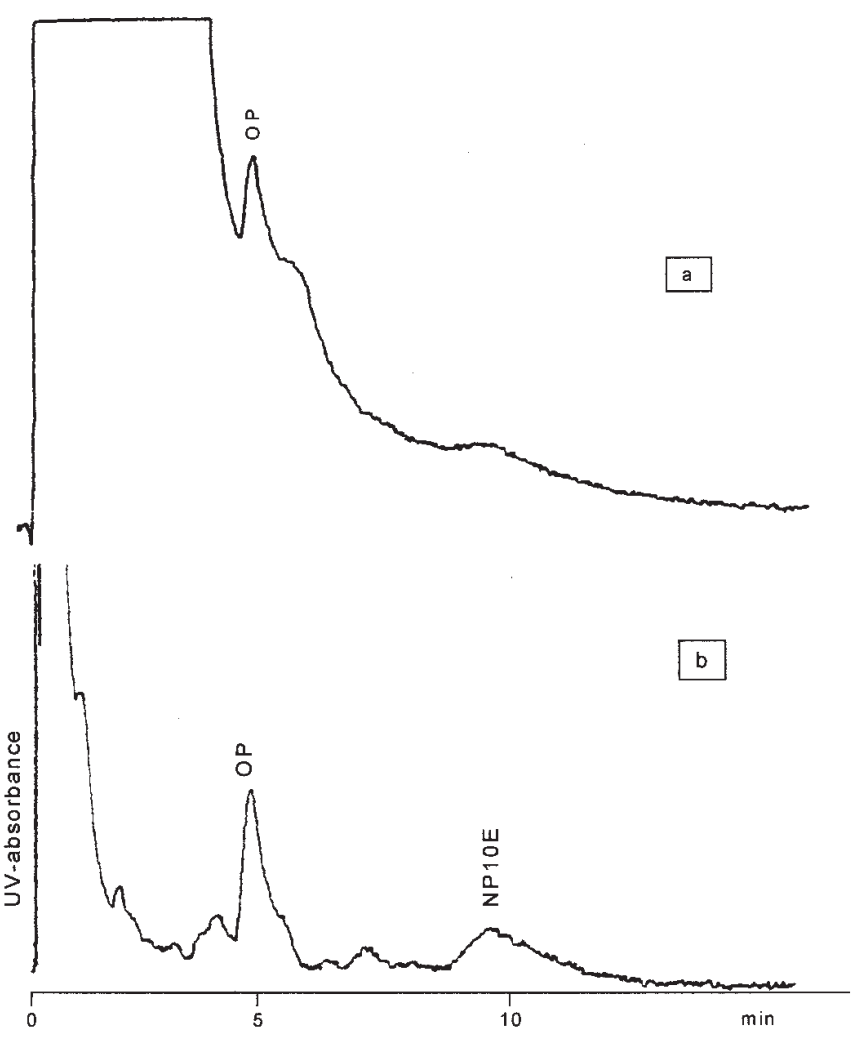

Figure 6. Comparison of efficiency of silica (a) and alumina (b) as sequential clean up adsorbents after MSPD extraction of trout. Samples were spiked with $10 \mu \mathrm{g} / \mathrm{g}$ of OP and $38 \mu \mathrm{g} / \mathrm{g}$ of NPEO $_{10}$. Conditions: RP-HPLC with UV detection $(\lambda=278 \mathrm{~nm})$.

Table I. Contribution of solid and aqueous fraction to total concentrations of nonylpheol and nonylphenol ethoxylates in samples from a domestic sewage treatment plant.

\begin{tabular}{|c|c|c|c|c|c|c|c|c|}
\hline \multirow[t]{2}{*}{ Sample } & \multicolumn{2}{|c|}{$\begin{array}{c}\text { Contribution of } \\
\text { AP/APEO in solid } \\
\text { fraction to } 1 \mathrm{~L} \text { sample } \\
(\mu \mathrm{g})\end{array}$} & \multicolumn{2}{|c|}{$\begin{array}{c}\text { Contribution of } \\
\text { AP/APEO in water } \\
\text { fraction to } 1 \mathrm{~L} \text { sample } \\
(\mu \mathrm{g})\end{array}$} & \multicolumn{2}{|c|}{$\begin{array}{l}\text { AP/APEO in solid + } \\
\text { water fraction added } \\
\quad(\mu \mathrm{g} / \mathrm{L}, \mu \mathrm{g} / \mathrm{kg})\end{array}$} & \multicolumn{2}{|c|}{$\begin{array}{l}\text { Determination of unfiltered } \\
\text { (total) sample } \\
(\mu \mathrm{g} / \mathrm{L})\end{array}$} \\
\hline & $N P$ & NP4EO & $N P$ & NP4EO & $N P$ & NP4EO & $N P$ & NP4EO \\
\hline STP influent & 7.0 & 11.3 & 7.4 & 45.6 & 14.3 & 56.8 & 11 & 81 \\
\hline STP effluent & 0.8 & 1.4 & 5.1 & 8.7 & 5.9 & 10.1 & 3.5 & 7.0 \\
\hline Primary sludge & 64 & 300 & 6.0 & 38.1 & 70 & 338 & \multicolumn{2}{|c|}{ not determined } \\
\hline
\end{tabular}




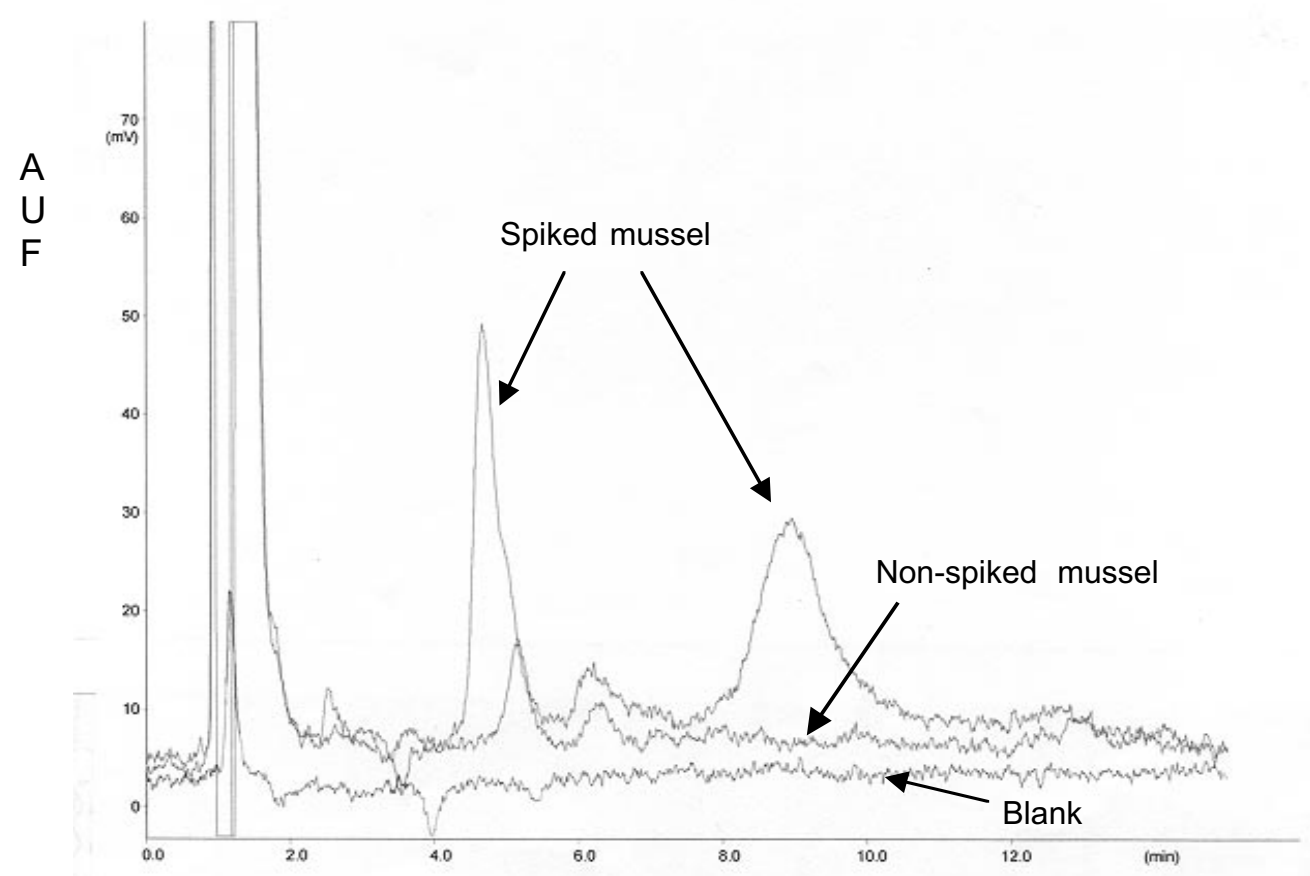

Figure 7. RP-HPLC-Flu chromatograms of extracts from mussel tissue obtained with the sequential MSPD-adsorption chromatography procedure. Spiked Mussel tissue contained $0.1 \mu \mathrm{g} \mathrm{OP} / \mathrm{g}$ and $0.3 \mu \mathrm{g} \mathrm{NPEO} / \mathrm{g}$ of tissue. Conditions: see figure 5 .

Average recoveries for all spiked tissue samples were greater than $90 \%$. Typical limits of detection amount to tens of ppbs on a wet weight basis.

In a field experiment with caged mussels placed upstream, in the discharge and downstream, respectively, from a domestic sewage treatment plant, accumulation of APEO in mussels could be demonstrated (see Fig. 8), illustrating the potential of the method for monitoring purposes.

\section{Environmental levels in abiotic compartments}

Environmental matrices and STP samples (see Fig. 4) have been analyzed successfully. Results are summarized in tables I and II.

The levels in STP samples from The Netherlands are in agreement with levels found in STPs elsewhere in Europe and North America (see Tab. II). Levels in effluents from
Dutch STPs tend to contain relatively low levels, indicative of effective treatment. Sewage treatment plants effectively remove APEO from influents and either transfer these to the sewage sludge or transform these into metabolites such as lower ethoxylate oligomers [notably NPEO and NP(EO) $)_{2}$, nonylphenol (NP) and carboxylated transformation products (see below). In samples from industrial STPs in The Netherlands, levels tend to be higher than in samples from domestic municipal STPs (see Tab. III).

Surface waters hardly contain any detectable amounts of APEO (see Tab. III). In general, octylphenol (OP) and octylphenol ethoxylates (OPE) were not present in environmental samples. NP and NPEO were present in most of the sediments and particulate matter samples analysed.

The results from analyses of marine sediments provide proof of the omnipresence of APEO in the environment. In

Table II. Overview of nonylphenol and nonylphenol polyethoxylates concentration ranges observed in sewage treament plants.

\begin{tabular}{lcccccc} 
Compounds & Influents & $\begin{array}{c}\text { Influents } \\
\text { Netherlands } \\
\mu g / L\end{array}$ & Effluents & $\begin{array}{c}\text { Effluents } \\
\text { Netherlands } \\
\mu g / L\end{array}$ & $\begin{array}{c}\text { Sewage } \\
\text { Sludge } \\
\mu g / g \text { d.w. }\end{array}$ & $\begin{array}{c}\text { Sewage } \\
\text { Sludge NL } \\
\mu g / g d . w .\end{array}$ \\
NP & $\mu g / L$ & $0-400$ & $0.1-760$ & $0-1.2$ & $2-2530$ & $0-2500$ \\
NPE & $3-2500$ & $2-480$ & $0-15$ & $8-900$ & $0-2400$ \\
\hline
\end{tabular}

(Sources: Thiele et al. 1997, De Voogt et al. 1997) 


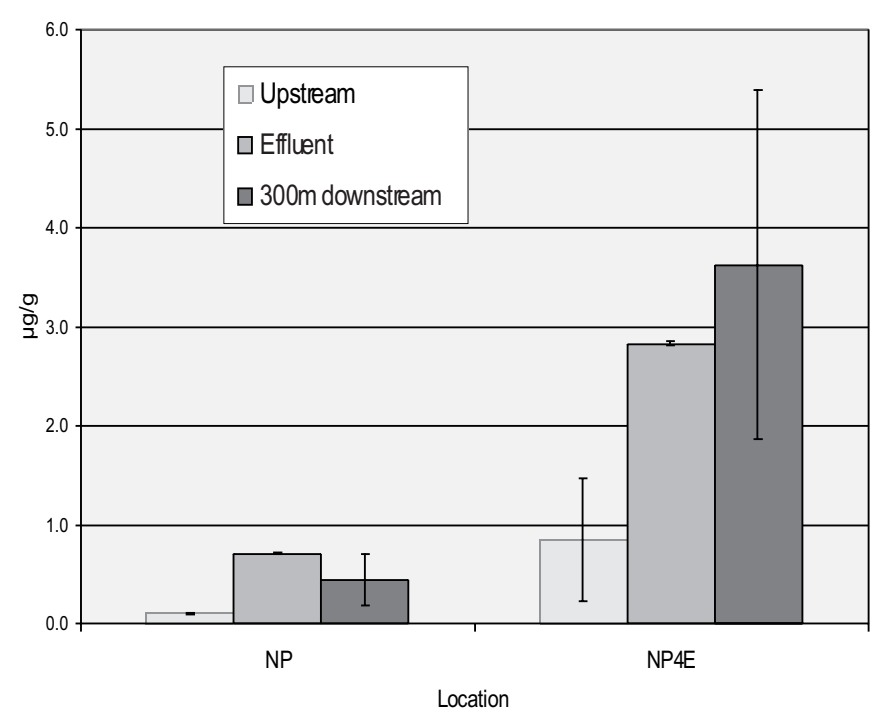

Figure 8. Biomonitoring of wastewater discharges of APEO using caged Zebra mussels and the MSPD method for extraction. Mean concentrations from 2 samples.

particular NPEO (nonylphenol monethoxylate), NP(EO) and $\mathrm{NP}(\mathrm{EO})_{3}$ are found, albeit at low levels, in marine and estuarine sediments. Recently we have also found evidence for the presence of carboxylated metabolites in estuarine waters (unpublished results).

\section{Biodegradation study}

The results of the laboratory experiment show that the primary degradation of $\mathrm{A}_{9} \mathrm{PEO}$ by the biofilm is relatively fast: more than $99 \%$ degradation is observed after 4 days (compared to e.g. 22 days for linear alkylbenzene sulfonates). It could be shown that the initial step of the degradation is $\omega$-carboxylation of the individual ethoxylate chains: metabolites with long carboxylated EO-chains are identified $\left(\mathrm{A}_{9} \mathrm{PE}_{\mathrm{n}} \mathrm{C}\right)$, see figure 9. After several days these are further degraded to short-chain carboxylated APEO with the most recalcitrant one being $\mathrm{A}_{9} \mathrm{PE}_{2} \mathrm{C}$. This degradation goes hand in hand with the oxidation of the nonyl chain leading to metabolites having both a carboxylated ethoxylate and alkyl chain of varying chain lengths (most abundant: $\mathrm{CA}_{9} \mathrm{PE}_{1} \mathrm{C}$ ). Both groups of metabolites are still present in the degradation setup after 25 days. Nonylphenol was not found as a metabolite in this study. As a result of these findings, the metabolic route presented in figure 10 is proposed as an alternative to the routes suggested in the literature $[5,6]$.

Table III. Concentration ranges of alkylphenols and alkylphenol ethoxylates detected in various matrices collected in The Netherlands.

\begin{tabular}{|c|c|c|c|c|}
\hline & NPEO & $N P$ & OPEO & $O P$ \\
\hline \multicolumn{5}{|c|}{ Environmental matrices } \\
\hline Surface waters ${ }^{a}$ & $<$ d.l. & $<$ d.I. -0.14 & $<$ d.I. & $<$ d.l. \\
\hline Sediments $^{b}$ & $2.6-5.7$ & $0.63-1.70$ & $<$ d.l. & $<$ d.I. \\
\hline Suspended matter ${ }^{\mathrm{C}}$ & $0.70-8.0$ & $0.21-0.62$ & $<$ d.I. -0.0003 & $<$ d.l. \\
\hline Marine sediments ${ }^{d}$ & $0.012-0.4$ & $0.0001-0.017$ & $0.0002-0.016$ & $<$ d.I. -0.002 \\
\hline \multicolumn{5}{|c|}{ Municipal waste water } \\
\hline Influente & $2.1-170$ & $<$ d.I. -23 & $<$ d.I. -27 & $<$ d.I. -0.1 \\
\hline Sewage sludge $f$ & $0.7-2400$ & $<$ d.I. -125 & $<$ d.I. -28 & $<$ d.I. -2 \\
\hline Effluent ${ }^{e}$ & $<$ d.I. -6.1 & $<$ d.I. -1.0 & $<$ d.I. -1.3 & $<$ d.I. -0.2 \\
\hline \multicolumn{5}{|c|}{ Industrial waste water } \\
\hline Influent ${ }^{\mathrm{e}}$ & $20-2270$ & $<$ d.I. -400 & $<$ d.I. -5350 & $<$ d.I. -100 \\
\hline Sewage sludge $f$ & $<$ d.I. -1400 & $<$ d.I. -2500 & $<$ d.I. -50 & $<$ d.I.-24 \\
\hline Effluent & $0.9-15$ & $<$ d.I. -1.2 & $<$ d.I. -8.7 & $<$ d.I. -0.13 \\
\hline
\end{tabular}

a in $\mu \mathrm{g} / \mathrm{L} ; n=3$, locations Kanaal Gent Terneuzen, Noordzeekanaal-IJmuiden, Nieuwe Waterweg-Beneluxtunnel;

${ }^{b}$ expressed in $\mathrm{mg} / \mathrm{g}$ dry matter; $n=3$, locations Kanaal Gent-Terneuzen, Noordzeekanaal-IJmuiden and Amerikahaven;

${ }^{c}$ expressed in $\mu \mathrm{g} / \mathrm{g}$ dry matter; $n=3$, locations Westerschelde-Terneuzen, Noordzeekanaal-IJmuiden en Nieuwe Waterweg-Beneluxtunnel;

${ }^{\mathrm{d}} \mu \mathrm{g} / \mathrm{g}$ dry matter; 22 estuarine and marine locations in North Sea and Irish Sea;

e in $\mu \mathrm{g} / \mathrm{L}$; total influent/effluent, i.e. including suspended matter present;

$f$ in $\mathrm{mg} / \mathrm{g}$ dry matter. 


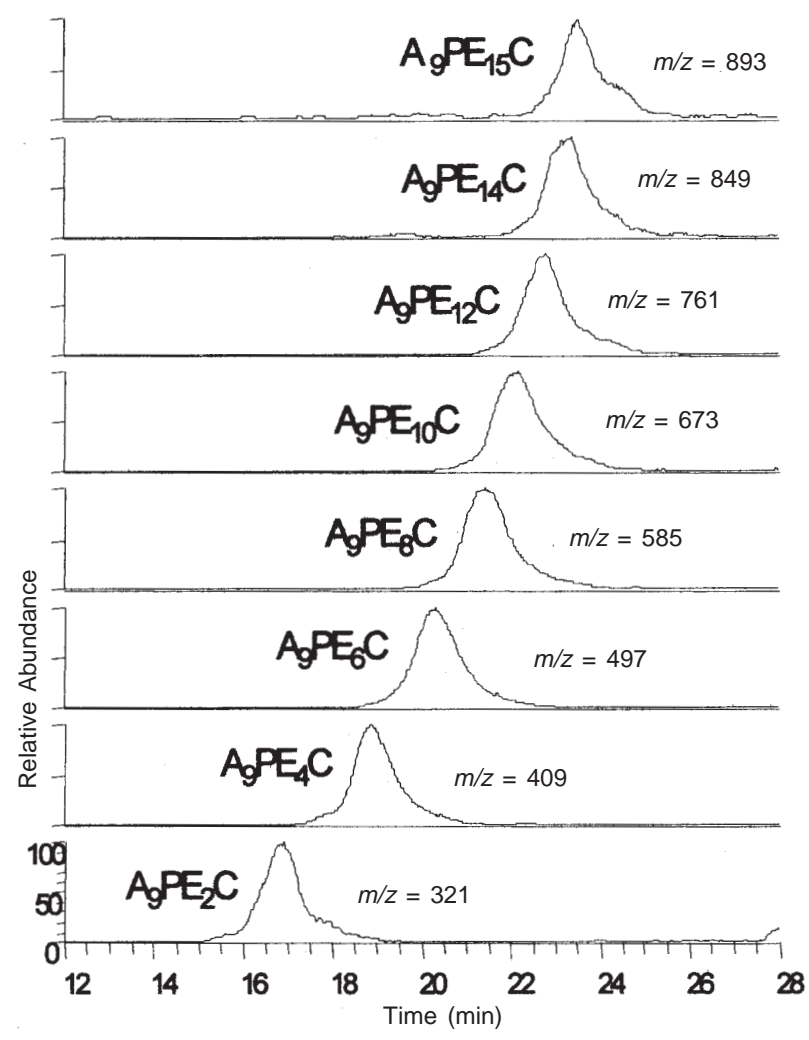

Figure 9. LC/ESMS ion extraction chromatogram from testwater extract of the biodegradation experiment showing the presence of long-chain nonylphenol ethoxycarboxylates (A9PEC).

\section{Conclusions}

Combined reversed/normal-phase LC with fluorescence detection or alternatively LC/MS provide efficient detection methods for APEO in environmental samples. Solid phase extraction is the method of choice for aqueous sample treatment. Aqueous samples containing relatively small amounts of particulate matter can be extracted directly (i.e. without filtration) on C-18 SPE. Soxhlet extraction or similar solid/liquid extraction methods are necessary for sediments, particulate matter, and sewage sludges, whereafter SPE can be employed for further clean up of extracts.
C-18 MSPD with sequential $\mathrm{Al}_{2} \mathrm{O}_{3}$ chromatography and methanol elution provides a rapid alternative for clean up of biological tissue for APEO analysis. Sample-matrix dependent additional clean up can be necessary.

Levels of nonylphenol and APEO in environmental and STP samples from The Netherlands confirm levels reported in the literature for European environments. Low levels of APEO can be found in relatively remote marine sediments, reflecting the relative recalcitrance of shorter-EO oligomer transformation products.

Biodegradation experiments revealed that aerobic primary biodegradation of APEO proceeds relatively fast in river water. Degradation starts with $\omega$-oxidation of the ethoxylate chain, leading to long-chain $\mathrm{A}_{9}$ PEC. No nonylphenol accumulates during the aerobic degradation of APE. Evidence is found that carboxylated transformation products, including the long-chain APEC, can also be present in the estuarine environment.

\section{Acknowledgements}

This work was supported by the EU Environment \& Climate Programme, project PRISTINE (ENV4-CT97-0494), and by the Dutch Ministry of Transport, Public Works and Water Management (projects SURTRANS, DIFFCHEM and LOES). We thank Dr. Thomas Knepper, ESWE Wiesbaden $(\mathrm{Ge})$, for providing the laboratory biodegradation set up facilities.

\section{References}

1. Kiewiet, A.T.; de Voogt, P. J. Chrom. A 1996, 733, 185-192.

2. De Voogt, P.; De Beer, K.; Van der Wielen, F. Tr. Anal. Chem. 1997, 16, 584-596.

3. Zhao, M.; van der Wielen, F.W.M.; de Voogt, P. J. Chromatogr. A 1999, 837, 129-138

4. Jonkers, C.C.A.; Knepper, T.P.; de Voogt, P. Environ Sci. Technol. 2001, 35, 335-340.

5. Thiele, B.; Gunther, K.; Schwuger, M.J. Chem. Rev. 1997, 97, 3247-3272.

6. Di Corcia, A.; Costantino, A.; Crescenzi, C.; Marinoni, E.; Samperi, R. Environ. Sci. Technol., 1998, 32, 2401-2409.

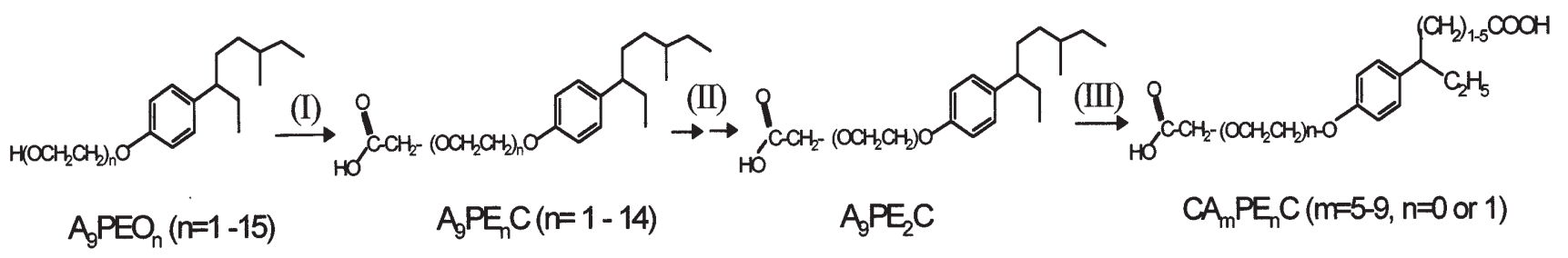

Figure 10. Newly proposed route for the biodegradation of APEO. 